
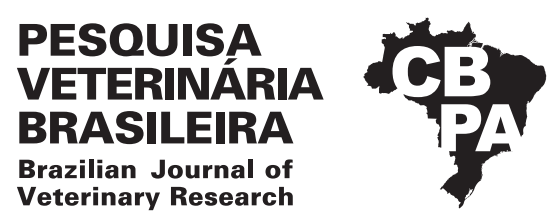

\title{
Detecção de Aeromonas spp. e do gene de virulência aerolisina em tilápias do Nilo (Oreochromis niloticus) com a técnica de mPCR ${ }^{1}$
}

\author{
Fernando J.P. Kim ${ }^{2 *}$, Allyne E.M Silva ${ }^{3}$, Rafael V.S Silva ${ }^{3}$, Pomy C.P Kim ${ }^{4}$, \\ Atzel Candido Acosta ${ }^{4}$, Suzianny M.B.C. Silva ${ }^{3}$, Maria J. Sena ${ }^{4}$ e Rinaldo A. Mota ${ }^{4}$
}

\begin{abstract}
Kim F.J.P., Silva A.E.M., Silva R.V.S., Kim P.C.P., Acosta A.C., Silva S.M.B.C., Sena M.J. \& Mota R.A. 2018. [Detection of Aeromonas spp. and virulence gene aerolysin in Nile tilapia (Oreochromis niloticus) using PCR technique.] Detecção de Aeromonas spp. e do gene de virulência aerolisina em tilápias do Nilo (Oreochromis niloticus) com a técnica de PCR. Pesquisa Veterinária Brasileira 38(9):1731-1735. Departamento de Desenvolvimento Educacional, Curso de Tecnologia em Agroecologia, Instituto Federal de Educação, Ciência e Tecnologia de Pernambuco, Campus Barreiros, Fazenda Sapé s/n, Zona Rural, Barreiros, PE 55560-000 Brazil. E-mail: fernando_kim@barreiros.ifpe.edu.br

Infections caused by bacteria of the genus Aeromonas are among the most common diseases in fish farming systems worldwide, and this disease occurs in all countries which have Nile tilapia (Oreochromis niloticus) farmed. The present work describes the development of a new multiplex PCR (mPCR) technique that diagnosis the genus Aeromonas and detects aerolysin gene (aerA). Reference strains of several Aeromonas species and other genera were used for standardization of mPCR. Strains of A. hydrophila from "pacaman" fish (Lophiosilurus alexandri) and Aeromonas spp. from Nile tilapia from farming systems were used too. Primers were designed based on the $16 \mathrm{~S}$ rRNA region and aerA (aerolysin toxin). To verify a better annealing temperature were used gradients between $59^{\circ} \mathrm{C}$ and $61^{\circ} \mathrm{C}$ with 40 ng of the DNA template. The $16 \mathrm{~S}$ rRNA gene and the aerA gene amplification products showed 786 and $550 \mathrm{bp}$, respectively. The $\mathrm{mPCR}$ showed better annealing temperature at $57.6^{\circ} \mathrm{C}$, and the detection limit for both genes (16S rRNA and aerA) was $10^{-10} \mathrm{~g} / \mu \mathrm{L}$ of the DNA. The standardized mPCR is quick, sensitive, and specific for Aeromonas spp. diagnosis and to detect aerolysin gene. This method showed advantages when compared to the conventional diagnostic methods and can be used in Nile tilapia or other fish farming systems. The detection of aerolysin gene is an important tool to determine the potential pathogenicity of Aeromonas spp. isolates.
\end{abstract}

INDEX TERMS: Aeromonas, gene, aerolysin, Nile tilapia, Oreochromis niloticus, PCR technique, mPCR, virulence factor, bacterioses.

RESUMO.- As infecções causadas por bactérias do gênero Aeromonas estão entre as doenças mais comuns em peixes cultivados em todo o mundo, com ocorrência de aeromoniose

\footnotetext{
${ }^{1}$ Recebido em 10 de novembro de 2017.

Aceito para publicação em 30 de novembro de 2017.

${ }^{2}$ Departamento de Desenvolvimento Educacional, Curso de Tecnologia em Agroecologia, Instituto Federal de Educação, Ciência e Tecnologia de Pernambuco (IFPE), Campus Barreiros, Fazenda Sapé s/n, Zona Rural, Barreiros, PE 55560-000, Brasil. *Autor para correspondência: fernando_kim@barreiros.ifpe.edu.br

${ }^{3}$ Departamento de Pesca e Aquicultura, Universidade Federal Rural de Pernambuco (UFRPE), Rua Dom Manuel, Dois irmãos, Recife, PE 52171-900, Brasil.

${ }^{4}$ Departamento de Medicina Veterinária, Universidade Federal Rural de Pernambuco (UFRPE), Rua Dom Manuel s/n, Dois irmãos, Recife, PE 52171-900.
}

em todos os países que possuem cultivo de tilápia do Nilo (Oreochromis niloticus). 0 presente trabalho descreve o desenvolvimento de uma nova multiplex PCR (mPCR) para diagnóstico de Aeromonas spp. e identificação do gene aerolisina (aerA). Para padronização da mPCR foram utilizadas cepas de referência de várias espécies do gênero Aeromonas e de outros gêneros. Também foram usadas cepas de campo de $A$. hydrophila oriundas de cultivos de peixes pacamãs (Lophiosilurus alexandri) e Aeromonas spp. de tilápias do Nilo. Os primers foram desenhados com base na região 16S rRNA e aerA. Para verificar a melhor temperatura de anelamento foram utilizados gradientes entre $59^{\circ} \mathrm{C}$ a $61^{\circ} \mathrm{C}$ com $40 \mathrm{ng}$ de DNA molde. Os produtos da amplificação da região 16S rRNA e do gene aerA apresentaram 786 e $550 \mathrm{pb}$, respectivamente. A mPCR apresentou melhor temperatura de anelamento a $57,6^{\circ} \mathrm{C}$ 
com limite de detecção das concentrações de DNA em ambos genes (16S rRNA and aerA) de $10^{-10} \mathrm{~g} / \mu \mathrm{L}$. A mPCR padronizada é rápida, sensível e específica no diagnóstico de Aeromonas spp. e identificação do gene aerolisina. Esta metodologia apresenta vantagens quando comparada aos métodos de diagnóstico convencionais, podendo ser utilizada em cultivos comerciais de tilápias do Nilo ou outros peixes. A identificação do gene aerolisina é uma importante ferramenta na determinação do potencial patogênico dos isolados de Aeromonas spp. estudados.

TERMOS DE INDEXAÇÃO: Aeromonas spp., gene de virulência, aerolisina, tilápias do Nilo, Oreochromis niloticus, técnica de PCR, mPCR, fator de virulência, bacterioses.

\section{INTRODUÇÃO}

Doenças causadas por bactérias do gênero Aeromonas são recorrentes no cultivo de tilápia e podem levar a quadros clínicos de anorexia, exoftalmia, lesões superficiais ou profundas no tegumento, acúmulo de líquido seroso no peritônio (ascite) e até septicemia hemorrágica (Pridgeon et al. 2013, Zhang et al. 2014). Dentre as várias espécies do gênero Aeromonas destaca-se Aeromonas hydrophila como uma das principais bactérias responsáveis por perdas em várias espécies de peixes cultivados (Zhang et al. 2014, Younes et al. 2015). De acordo com Lacerda et al. (2015), apesar de Aeromonas spp. e neste gênero a espécie $A$. hydrophila ser bem conhecida como causadora de mortalidades na piscicultura, muitas vezes o diagnóstico é limitado, já que outros agentes infecciosos podem causar sinais clínicos similares.

As técnicas moleculares como a reação em cadeia da polimerase (PCR) possuem vantagens em relação aos métodos microbiológicos convencionais de identificação, como a rapidez no diagnóstico e a especificidade para o agente investigado. 0 uso desta técnica permite a identificação de genes associados à resistência a antimicrobianos, bem como o estudo de fatores de virulência das cepas (Abu-Elala et al. 2015), permitindo determinar o grau potencial de patogenicidade de uma cepa de interesse (Onuk et al. 2013).

Numerosos genes de virulência são encontrados em Aeromonas spp., incluindo genes de produção de flagelo lateral (Gavín et al. 2002, Canals et al. 2006) e os genes que codificam proteínas extracelulares como nucleases, lipases, proteases e aerolisina (Pemberton et al. 1997, Onuk et al. 2013, Nagar et al. 2016). Segundo Ye et al. (2013), a aerolisina, uma enterotoxina citolítica, é o fator de virulência mais conhecido e caracterizado, sendo codificado pelo gene aerA. A aerolisina se liga a um receptor específico glicoprotéico sobre a superfície de células eucarióticas, formando orifícios de cerca de $3 \mathrm{~nm}$ de diâmetro, levando a morte celular por perda da permeabilidade seletiva (Hu et al. 2012, Ye et al. 2013).

Neste estudo objetivou-se desenvolver um método de identificação rápido e sensível para detectar Aeromonas spp. baseado na amplificação de um fragmento do gene $16 S$ rRNA e identificar cepas portadoras do fator de virulência codificado pelo gene aerA mediante um ensaio de multiplex PCR.

\section{MATERIAL E MÉTODOS}

Cepas bacterianas de referência. Para padronização e controle das reações de PCR, foram utilizadas cepas bacterianas de referência cedidas pela Fundação Oswaldo Cruz: Aeromonas hydrophila
(ATCC 7966), Aeromonas sobria (ATCC 43979), Aeromonas media (ATCC 33907), Aeromonas caviae (ATCC 15468), Aeromonas sp. (ATCC 35941), Pseudomonas aeruginosa (ATCC 19429) e Streptococcus agalactiae (ATCC 13813).

Amostras de campo de Aeromonas spp. e Aeromonas hydrophila. 0 estudo foi aprovado pelo Comitê de Ética no Uso de Animais da Universidade Federal Rural de Pernambuco (UFRPE) sob o número de licença 23082.009199/2014-55.

Foram utilizados 16 isolados de Aeromonas spp. obtidos de tilápias (Oreochromis niloticus) doentes, sendo oito isolados provenientes de Jatobá e oito isolados de Petrolândia, ambos municípios pertencentes ao estado de Pernambuco, Brasil. Também foram incluídos no estudo dois isolados de Aeromonas hydrophila, previamente identificados através de PCR, provenientes de pacamãs (Lophiosilurus alexandri) doentes oriundos do Vale do São Francisco, cedidas pelo Laboratório de Microbiologia e Imunologia Animal da Universidade Federal do Vale do São Francisco (Univasf).

As cepas bacterianas foram semeadas em placas contendo ágar base enriquecido com $5 \%$ de sangue ovino desfibrinado e incubadas a $28^{\circ} \mathrm{C}$ por $24 \mathrm{~h}$. Após a incubação, as colônias suspeitas foram suspendidas em $1,5 \mathrm{~mL}$ de caldo BHI e incubadas a $28^{\circ} \mathrm{C}$ por $24 \mathrm{~h}$. Em seguida foi realizada a extração de DNA das colônias, utilizando o Kit comercial "Genomic DNA Purification" (PROMEGA $\left.{ }^{\circledR}\right)$, adotando o protocolo do fabricante.

Padronização da mPCR. Os ensaios da mPCR para detectar Aeromonas spp. e o gene aerA em Aeromonas hydrophila foram realizados com o uso dois primers (Quadro 1) desenhados com a ferramenta Primer Blast (https://blast.ncbi.nlm.nih.gov/Blast.cgi). Para o desenho dos primers de amplificação do gênero Aeromonas foi utilizado como alvo o gene $16 S$ ribossomal (16S $r R N A$ ) e para o estudo do fator de virulência foi selecionado o gene aerolisina citotóxica enterotóxica (aerA).

As reações foram realizadas em volume final de $20 \mu \mathrm{L}$, contendo $40 \mathrm{ng}$ de DNA molde, $10 \mathrm{pmol} / \mu \mathrm{L}$ de cada primer, $12 \mu \mathrm{L}$ da solução Go $\mathrm{Taq}^{\circledR}$ Green Master Mix (Go Taq ${ }^{\circledR}$ Green Master Mix, Promega, Madison, WI, USA) e $2 \mu \mathrm{L}$ de água ultrapura. As condições de amplificação consistiram em: dez minutos a $95^{\circ} \mathrm{C}$ (etapa inicial de desnaturação), seguido por 30 ciclos de um minuto a $95^{\circ} \mathrm{C}$, um minuto para o anelamento e um minuto a $72^{\circ} \mathrm{C}$, finalizando com uma extensão a $72^{\circ} \mathrm{C}$ por dez minutos. Para estabelecer a melhor temperatura de anelamento foram utilizados gradientes de temperatura de $59^{\circ} \mathrm{C}$ a $61^{\circ} \mathrm{C}$ contendo $40 \mathrm{ng}$ de DNA molde. Foram realizados num primeiro momento a PCR individual para cada gene e no segundo momento a MPCR, utilizando o conjunto de todos os primers.

Para analisar o limite de detecção da MPCR foram realizadas diluições seriadas do DNA extraído das cepas, entre $10^{-8} \mathrm{a} 10^{-14} \mathrm{~g} / \mu \mathrm{L}$, sendo o material genético quantificado e avaliado quanto a seu grau de pureza por absorbância utilizando espectrofotômetro Multiskan ${ }^{\text {TM }}$ GO Microplate a 260 e 280nm. Para testar a especificidade da técnica foi utilizado DNA de cepas de referência não pertencentes ao gênero Aeromonas. Como controle negativo de todos os testes foi empregada

Quadro 1. Características dos primers utilizados na mPCR

\begin{tabular}{ccccc}
\hline Primer & Sequência & GC(\%) & Ta $\left({ }^{\circ} \mathrm{C}\right)^{*}$ & Amplicon \\
\hline $16 S$ - F & 5'-TGACGTTACTCGCAGAGGA-3' & $52,6 \%$ & $53,3^{\circ} \mathrm{C}$ & $786 \mathrm{pb}$ \\
$16 S$ - R & 5'-GCTTGCAGCCCTCTGTACG- 3' & $63,2 \%$ & $58,7^{\circ} \mathrm{C}$ & \\
aerA - F & 5'-GTACAACCTGGACCCTGACA-3' & $55 \%$ & $56,5^{\circ} \mathrm{C}$ & $550 \mathrm{pb}$ \\
aerA - R & 5'-CCCACTGGTAACGAATGCTG- 3' & $55 \%$ & $56,1^{\circ} \mathrm{C}$ &
\end{tabular}

* Temperatura de anelamento. 
água ultrapura livre de nuclease. Após a amplificação foi realizada a eletroforese utilizando gel de agarose a 1,5\%, os produtos da PCR foram corados com BlueGreen (LGC Biotecnologia ${ }^{\circledR}$ ), posteriormente visualizados em transiluminador e fotodocumentados sob luz UV para detecção de peso molecular específico para o fragmento amplificado pelos primers utilizados, empregando um marcador de peso molecular de 100pb para comparações.

\section{RESULTADOS}

Todos os primers desenhados para a detecção de Aeromonas spp. e identificação do gene aerA foram amplificados em todas as cepas de Aeromonas utilizadas, exibindo amplicon com pesos moleculares compatíveis aos esperados (786pb na região $16 \mathrm{~S}$ rRNA e 550pb no gene aerA). As temperaturas de anelamento testadas separadamente para os primers $16 S$ rRNA e aerA foram respectivamente de $57,8^{\circ} \mathrm{C}$ e $57,2^{\circ} \mathrm{C}$, com amplificações positivas em concentrações de DNA até $10^{-10} \mathrm{~g} / \mu \mathrm{L}$ para ambos pares de primers.

Para o gene aerA foram positivos 15 isolados (Quadro 2). Nos testes de especificidade, utilizando as cepas de Streptococcus agalactiae e Pseudomonas aeruginosa não foram observadas amplificações quando utilizados os primers $16 \mathrm{~S}$ rRNA e aerA, tanto de forma individual como em conjunto na mPCR.

A mPCR apresentou melhores resultados de amplificação na temperatura de anelamento a $57,6^{\circ} \mathrm{C}$ com limite de detecção nas concentrações de DNA até $10^{-10} \mathrm{~g} / \mu \mathrm{L}$ (Fig.1).

\section{Quadro 2. Resultado dos isolados no teste mPCR} padronizada para os genes $16 S$ rRNA e aerA

\begin{tabular}{|c|c|c|}
\hline \multirow{2}{*}{ Isolados } & \multicolumn{2}{|c|}{ Genes } \\
\hline & $16 S$ rRNA & aerA \\
\hline Aeromonas hydrophila (ATCC 7966) & + & - \\
\hline A. sobria (ATCC 43979) & + & - \\
\hline A. media (ATCC 33907) & + & - \\
\hline A. caviae (ATCC 15468) & + & - \\
\hline Aeromonas sp. (ATCC 35941) & + & - \\
\hline Streptococcus agalactiae (ATCC 13813) & - & - \\
\hline Pseudomonas aeruginosa (ATCC 19429) & - & - \\
\hline MTP01 A. hydrophila (amostra de campo) & + & + \\
\hline MTP02 A. hydrophila (amostra de campo) & + & + \\
\hline J1024 (amostra de campo) & + & - \\
\hline J1064 (amostra de campo) & + & + \\
\hline J1071 (amostra de campo) & + & + \\
\hline J2011 (amostra de campo) & + & + \\
\hline J2012 (amostra de campo) & + & - \\
\hline J2013 (amostra de campo) & + & + \\
\hline P3011 (amostra de campo) & + & + \\
\hline P3012 (amostra de campo) & + & + \\
\hline P3014 (amostra de campo) & + & + \\
\hline P4201 (amostra de campo) & + & + \\
\hline P4171 (amostra de campo) & + & - \\
\hline P4172 (amostra de campo) & + & + \\
\hline J1D1 (amostra de campo) & + & + \\
\hline J1D2 (amostra de campo) & + & + \\
\hline P2D1 (amostra de campo) & + & + \\
\hline P3D2 (amostra de campo) & + & + \\
\hline
\end{tabular}

\section{DISCUSSÃO}

Bactérias do gênero Aeromonas são uma importante causa de mortalidade em tilápias e outros peixes de cultivos em todo o mundo (Oliveira et al. 2012, Ye et al. 2013, Zhang et al. 2014, Abu-Elala et al. 2015, Younes et al. 2015). Desta forma, a busca por técnicas mais sensíveis e específicas aumentam a possibilidade de um diagnóstico rápido e específico para infecções causadas por estes patógenos.

Vários métodos de diagnóstico molecular são baseados no sequenciamento para determinar a espécie causadora da aeromoniose (Hu et al. 2012, Ye et al. 2013). 0 sequenciamento do DNA para diagnóstico tem como benefício a alta especificidade para o agente etiológico, bem como a comparação de similaridades entre diferentes isolados servindo para estudos epidemiológicos e de sistemática. Apesar disso, o alto custo do sequenciamento pode inviabilizar esse método na rotina de diagnóstico.

Clarridge (2004), analisando a sequência $16 S$ rRNA para identificação bacteriana afirma que o uso desse gene constitui uma forma robusta, precisa e de fácil reprodução na identificação bacteriana. Em nosso estudo, o uso do gene $16 S$ rRNA como alvo para a identificação do gênero Aeromonas foi embasado nos trabalhos realizados por Figueras et al. (2000), Lee et al. (2002) e Morandi et al. (2005).

Alguns estudos realizados anteriormente tiveram como objetivo a padronização de ensaios de MPCR visando a amplificação simultânea de várias espécies de bactérias patogênicas para espécies de peixes de cultivo continental e marinho (Del Cerro et al. 2002, Mata et al. 2004, Tsai et al. 2012, Zhang et al. 2014), sendo nesses estudos identificada A. hydrophila utilizando a região $16 S$ rRNA com posterior sequenciamento e análise filogenética do amplicon.

Chu \& Lu (2005) padronizaram um diagnóstico por PCR convencional para A. hydrophila utilizando apenas a região $16 S$ rRNA com a identificação da bactéria apenas pela visualização da banda evidenciada em gel de agarose, sem posterior sequenciamento e análise de similaridade do amplicon. Utilizando a ferramenta Primer Blast (https:// blast.ncbi.nlm.nih.gov/Blast.cgi) para análise dos primers da região $16 S$ rRNA utilizados por Chu \& Lu (2005) não foi possível determinar diferenças significativas e constantes na similaridade entre $A$. hydrophila e as demais espécies do

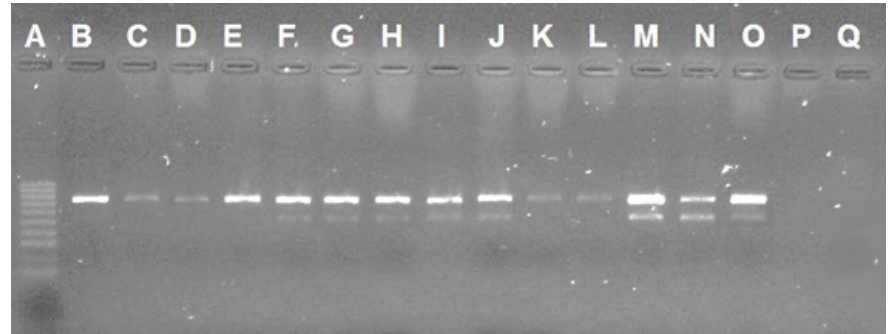

Fig.1. Gel de agarose dos produtos amplificados para multiplex PCR com DNA das cepas a $10^{-10} \mathrm{~g} / \mu \mathrm{L}$. (A) Marcador molecular 100pb, (B) Aeromonas hydrophila ATCC 7966, (C) A. sobria ATCC 43979, (D) A. caviae ATCC 15468, (E) Aeromonas sp. ATCC 35941, (F) MTP01 (A. hydrophila), (G) MTP02 (A. hydrophila), (H) P4172, (I) P3D2, (J) P2D1, (K) P4171, (L) J2012, (M) J1064, (N) J1071, (O) J1D2, (P) Pseudomonas aeruginosa ATCC 19429, (Q) controle negativo água. 
gênero Aeromonas, sendo considerado pouco eficiente o uso apenas dessa região para amplificação de $A$. hydrophila sem o devido sequenciamento.

A aerolisina é uma proteína termolábil que apresenta alta similaridade com a $\alpha$-toxina de Clostridium perfringens com mecanismo de ação formando poros na membrana do hospedeiro (Chakraborty et al. 1986, Chopra \& Houston 1999, Cole et al. 2004). Hu et al. (2012), Oliveira et al. (2012) e Ye et al. (2013) trabalharam com a caracterização de fatores de virulência em $A$. hydrophila oriundas de peixes doentes, encontrando o fator de virulência aerolisina enterotoxina citolítica presente em mais de $80 \%$ das amostras analisadas. Outros fatores de virulência também podem ser encontrados associados à mortalidade em peixes, mas geralmente em menor proporção quando comparados à aerolisina (Chopra \& Houston 1999, Hu et al. 2012).

Em nossas análises de similaridade, utilizando DNA plasmidial das diferentes espécies de Aeromonas que possuíam aerolisina, foi verificada a ocorrência de uma região conservada nas amostras sequenciadas de $A$. hydrophila catalogadas no GeneBank, direcionando o desenho dos primers deste trabalho.

Em nosso estudo, o fator de virulência aerolisina foi detectado em $83,33 \%$ das amostras de campo de peixes doentes, demonstrando a grande importância desse gene na patogenia da aerominose, doença responsável pelas altas taxas de mortalidade nas tilapiculturas. Nossos resultados juntam-se aos previamente obtidos por Chacón et al. (2003), que observaram uma maior frequência do gene aerA junto a outros fatores de virulência em isolados de Aeromonas spp. oriundos de casos clínicos quando comparados com isolados de origem ambiental.

A mPCR descrita neste trabalho permite a identificação simultânea do gênero Aeromonas e identificação do gene fator de virulência aerolisina, resultando numa metodologia simples e mais econômica quando comparada as técnicas previamente descritas como o sequenciamento. Os menores custos econômicos permitem a implementação de tal metodologia na rotina de diagnóstico em diferentes laboratórios, contribuindo com o desenvolvimento da piscicultura.

\section{CONCLUSÃO}

A mPCR desenvolvida demonstrou um adequado limite de detecção e especificidade, capaz de diferenciar bactérias do gênero Aeromonas e ainda permitindo a identificação de cepas portadoras do gene fator de virulência aerA, podendo ser utilizada na detecção de bactérias causadoras da aeromoniose em tilápias, outros peixes cultivados ou qualquer organismo que seja suscetível a esse agente.

Agradecimento.- À FACEPE pela concessão das bolsas PIBIC (BIC-1862-5.05/15 e BIC-1891-5.05/15). À Professor Mateus Matiuzzi Costa da Universidade Federal do Vale do São Francisco (Univasf) e à Fundação Oswaldo Cruz pelas cepas bacterianas de referência cedida.

\section{REFERÊNCIAS}

Abu-Elala N., Abdelsalam M., Marouf S. \& Setta A. 2015. Comparative analysis of virulence genes, antibiotic resistance and gyrB-based phylogeny of motile Aeromonas species isolates from Nile tilapia and domestic fowl. Lett. Appl. Microbiol. 61(5):429-436. <http://dx.doi.org/10.1111/lam.12484> $<$ PMid:26280543>
Canals R., Altarriba M., Vilches S., Horsburgh G., Shaw J.G., Tomás J.M. \& Merino S. 2006. Analysis of the lateral flagellar gene system of Aeromonas hydrophila AH-3. J. Bacteriol. 188(3):852-862.<http://dx.doi.org/10.1128/ JB.188.3.852-862.2006><PMid:16428388>

Chacón M.R., Figueras M., Castro-Escarpulli G., Soler L. \& Guarro J. 2003. Distribution of virulence genes in clinical and environmental isolates of Aeromonas spp. Antonie van Leeuwenhoek 84(4):269-278. <http://dx.doi. org/10.1023/A:1026042125243><PMid:14574104>

Chakraborty T., Huhle B., Bergbauer H. \& Goebel W. 1986. Cloning, expression, and mapping of the Aeromonas hydrophila aerolysin gene determinant in Escherichia coli K-12. J. Bacteriol. 167(1):368-374. <http://dx.doi. org/10.1128/jb.167.1.368-374.1986><PMid:3522552>

Chopra A.K. \& Houston C.W. 1999. Enterotoxins in Aeromonas-associated gastroenteritis. Microb. Infect.1(13):1129-1137.<http://dx.doi.org/10.1016/ S1286-4579(99)00202-6><PMid:10572317>

Chu W.H. \& Lu C.P. 2005. Multiplex PCR assay for the detection of pathogenic Aeromonas hydrophila. J. Fish Diseases. 28(7):437-441. <http://dx.doi. org/10.1111/j.1365-2761.2005.00628.x ><PMid:16083449>

Clarridge 3rd J.E. 2004. Impact of 16S rRNA gene sequence analysis for identification of bacteria on clinical microbiology and infectious diseases. Clin. Microbiol. Rev. 17(4):840-862. <http://dx.doi.org/10.1128/ CMR.17.4.840-862.2004><PMid:15489351>

Cole A.R., Gibert M., Popoff M., Moss D.S., Titball R.W. \& Basak A.K. 2004. Clostridium perfringens epsilon-toxin shows structural similarity to the pore-forming toxin aerolysin. Nat. Struct. Mol. Biol.11(8):797-798. <http:// dx.doi.org/10.1038/nsmb804> <PMid:15258571>

Del Cerro A., Marquez I. \& Guijarro J. 2002. Simultaneous detection of Aeromonas salmonicida, Flavobacterium psychrophilum, and Yersinia ruckeri, three major fish pathogens, by multiplex PCR. Appl. Environ. Microbiol. 68(10):5177-5180. <http://dx.doi.org/10.1128/AEM.68.10.51775180.2002><PMid:12324372>

Figueras M.J., Guarro J. \& Martínez-Murcia A. 2000. Use of restriction fragment length polymorphism of the PCR-amplified 16S rRNA gene for the identification of Aeromonas spp. J. Clin. Microbiol. 38(5):2023-2025. <PMid:10866546>

Gavín R., Rabaan A.A., Merino S., Tomás J.M., Gryllos I. \& Shaw J.G. 2002. Lateral flagella of Aeromonas species are essential for epithelial cell adherence and biofilm formation. Mol. Microbiol. 43(2):383-397. <http://dx.doi. org/10.1046/j.1365-2958.2002.02750.x><PMid:11985716>

Hu M., Wang N., Pan Z., Lu C. \& Liu Y. 2012. Identity and virulence properties of Aeromonas isolates from diseased fish, healthy controls and water environment in China. Lett. Appl. Microbiol. 55(3):224-233. <http://dx.doi. org/10.1111/j.1472-765X.2012.03281.x><PMid:22725694>

Lacerda I.P.S., Goncalves Y.S., Oliveira S.T.L., Demarqui F.N., Krewer C.C., Gouveia G.V., Félix W.P. \& Costa M.M. 2015. Efficacy of Aeromonas hydrophila S-layer bacterins with different protein profiles as a vaccine in Nile tilapia (Oreochromis niloticus). Afr. J. Microbiol. Res. 9(29):1770-1777. <http:// dx.doi.org/10.5897/AJMR2015.7586>

Lee C., Cho J.C., Lee S.H., Lee D.G. \& Kim S.J. 2002. Distribution of Aeromonas spp. as identified by $16 \mathrm{~S}$ rDNA restriction fragment length polymorphism analysis in a trout farm. J. Appl. Microbiol. 93(6):976-985. <http://dx.doi. org/10.1046/j.1365-2672.2002.01775.x><PMid:12452953>

Mata A., Gibello A., Casamayor A., Blanco M., Domínguez L. \& FernándezGarayzábal J. 2004. Multiplex PCR assay for detection of bacterial pathogens associated with warm-water streptococcosis in fish. Appl. Environ. Microbiol. 70(5):3183-3187.<http://dx.doi.org/10.1128/AEM.70.5.3183-3187.2004> $<$ PMid:15128589>

Morandi A., Zhaxybayeva O., Gogarten J.P. \& Graf J. 2005. Evolutionary and diagnostic implications of intragenomic heterogeneity in the 16S rRNA gene in Aeromonas strains. J. Bacteriol. 187(18):6561-6564. <http://dx.doi. org/10.1128/JB.187.18.6561-6564.2005><PMid:16159790> 
Nagar V., Bandekar J.R. \& Shashidhar R. 2016. Expression of virulence and stress response genes in Aeromonas hydrophila under various stress conditions. J. Basic. Microbiol. 56(10):1132-1137. <http://dx.doi.org/10.1002/ jobm.201600107> <PMid:27163835>

Oliveira S.T., Veneroni-Gouveia G. \& Costa M.M. 2012. Molecular characterization of virulence factors in Aeromonas hydrophila obtained from fish. Pesq. Vet. Bras. 32(8):701-706. <http://dx.doi.org/10.1590/S0100-736X2012000800004>

Onuk E., Findik A., Turk N., Altun S., Korun J., Ozer S., Avsever M. \& Ciftci A. 2013. Molecular identification and determination of some virulence genes of Aeromonas spp. in fish and water from Turkish coastal regions. Rev. Méd. Vét. 164:200-206.

Pemberton J.M., Kidd S.P. \& Schmidt R. 1997. Secreted enzymes of Aeromonas. FEMS Microbiol. Lett. 152(1):1-10. <http://dx.doi.org/10.1111/j.1574-6968.1997. tb10401.x> <PMid:9228763>

Pridgeon J.W., Klesius P.H., Song L., Zhang D., Kojima K. \& Mobley J.A. 2013. Identification, virulence, and mass spectrometry of toxic ECP fractions of West Alabama isolates of Aeromonas hydrophila obtained from a 2010 disease outbreak. Vet. Microbiol. 164(3/4):336-343. <http://dx.doi. org/10.1016/j.vetmic.2013.02.020> <PMid:23523171>

Tsai M.A., Ho P.Y., Wang P.C., e Y.J., Liaw L.L. \& Chen S.C. 2012. Development of a multiplex polymerase chain reaction to detect five common Gram-negative bacteria of aquatic animals. J. Fish Diseases 35(7):489-495.<http://dx.doi. org/10.1111/j.1365-2761.2012.01372.x><PMid:22571515>

Ye Y., Fan T., Li H., Lu J., Jiang H., Hu W. \& Jiang Q. 2013. Characterization of Aeromonas hydrophila from hemorrhagic diseased freshwater fishes in Anhui Province, China. Int. Food Res. J. 20:1449-1452.

Younes A., Gaafar A. \& Awad E.S. 2015. Virulence determinants and plasmid profile of Aeromonas hydrophila strains isolated from Oreochromis niloticus. Glob. Vet. 15:613-617.

Zhang X., Yang W., Wu H., Gong X. \& Li A. 2014. Multilocus sequence typing revealed a clonal lineage of Aeromonas hydrophila caused motile Aeromonas septicemia outbreaks in pond-cultured cyprinid fish in an epidemic area in central China. Aquaculture 432:1-6. <http://dx.doi.org/10.1016/j. aquaculture.2014.04.017> 